\title{
A Note on Leibniz's Supposed Flirtation with Occasionalism in the 1669 Letter to Thomasius
}

\section{Nicholas Okrent}

University of North Carolina - Chapel Hill

In his article "Leibniz: Physics and Philosophy", Daniel Garber asserts that the early Leibniz was a mechanist and believed that "only God has the ability to move bodies by continually recreating them in different places....". Garber believes that these views, which Leibniz explicitly holds in the 1669 letter to Thomasius, support his claim that Leibniz accepted a version of occasionalism in that letter ${ }^{2}$. Garber's case is a strong one, for the letter to Thomasius develops ideas that are quite suggestive of occasionalism.

Nonetheless, this paper argues that Leibniz does not hold an occasionalistic notion of causation in the 1669 letter to Thomasius. Garber mistakenly ascribes occasionalism to the early Leibniz because he interprets Leibniz's views within a Cartesian framework. Only by understanding how Leibniz's Aristotelian concept of substance in the 1669 letter to Thomasius leads to a metaphysics quite distinct from Cartesianism ${ }^{3}$ will it be clear why the ideas developed in that letter do not amount to occasionalism ${ }^{4}$.

Leibniz makes at least four claims in the letter to Thomasius that are remarkably similar to claims made by Descartes. First, Leibniz accepts the signature feature of mechanical philosophy that "only magnitude, figure, and motion are to be used in explaining corporeal properties".5. Second, Leibniz rejects the scholastic notion of substantial forms in which "a kind of immaterial being, though insensible in bodies...spontaneously imparts motion to a body...without the help of an external thing", not cause motion in itself, nor can motion arise out of matter spontaneously (i.e., without an external cause). Leibniz argues that because "we can assume nothing in bodies which does not follow from the definition of extension and antitypy [the attributes of matter,]...there is no motion, strictly speaking, as a real entity in bodies"7. Finally, motion is explained by God's constantly creating things ex nihilo ${ }^{8}$. 
These four commitments are recognizably Cartesian and are at least suggestive of occasionalism. The following argument is familiar from long use in the context of discussions regarding Cartesians and Cartesianism. Leibniz writes, "I have demonstrated...that whatever moves is continuously created [by God] and that bodies are something at any instant in assignable motion, but that they are nothing at any time midway between the instants in motion.... I have found out...about the perpetual creation [by God] involved in motion....". . In other words, the continuing existence of finite things depends on God's constant 'conservation' of things by perpetually creating them anew.

As will become clear, constant creation does not by itself entail occasionalism because finite things could be created with the power to cause things to happen. Finite things created with causal powers could themselves be secondary causes insofar as God continues to conserve them. Consequently, establishing conservatism does not establish occasionalism.

At this point, a brief discussion of the traditional distinctions between conservatism, occasionalism and concurrentism will be useful. Conservatism is the view that things exist only because God constantly sustains them or, as Descartes and Leibniz hold, constantly recreates them ex nihilo. Occasionalism is the view that every natural phenomenon has God as its primary or first cause and, furthermore, that God is the only cause of such phenomena. An occasionalist believes that there are no genuine secondary (i.e., creaturely) causes in nature ${ }^{10}$. Concurrentism is similar to occasionalism in that both views accept God as an immediate cause of every natural phenomenon. However, concurrentists argue that corporeal substances have causal powers that are independent of the causal power of God: "Such powers are not, they insist, supplanted or rendered otiose by God's causal activity in the world. Instead, God contributes to the ordinary course of nature only as a universal or general cause who cooperates with or concurs with secondary causes""l!.

The fourth of the above mentioned claims from the 1669 letter to Thomasius establishes that Leibniz accepted conservatism. However, conservatism is compatible with both occasionalism and concurrentism. Occasionalism follows only if there are no sec- 
ondary causes acting as at least partial causes distinct from the primary cause (i.e., God). The scholastics, who claimed that there are secondary causes, had little difficulty explaining the possibility of creaturely causation because their picture of the universe contained dynamic substantial forms which endowed finite things with the power to cause action. The mechanists' situation was different. They believed that all corporeal properties could be explained in terms of magnitude, figure and motion, and they believed that all changes in corporeal things were explainable in terms of motion. For the Cartesian, however, corporeal bodies consist solely of matter (res extensa), while motion is not a property of and cannot be produced by matter.

Descartes never included causal efficacy in his lists of the qualities of extension. Indeed, causal efficacy, as a real quality or capacity, might be incompatible with Descartes' geometric picture of the world, which consists of nothing but extended substance and its modes. As Rodis-Lewis writes, "Descartes fonde...l'autonomies de la physique mécaniste: le mode de l'objectivité scientifique est purifié de son revêtement qualitatif et de tout dynamisme interne"12. If Rodis-Lewis is correct in claiming that Descartes succeeded in describing a universe without qualities or internal dynamic powers, then it is hard to see how corporeal body could be or have within it a secondary cause of motion. If one corporeal body (A) strikes another (B) which then changes in some way and occasionalism is rejected, then there must be something about $A$ that is at least a partial cause of B's changing. Given Descartes' mechanistic physics, the cause of the change in B must be the motion moving its parts. By definition, however, motion is not a real entity in matter: there is nothing to be transferred from $A$ to $B$. Furthermore, $A$ has no internal causal power by which it could cause $B$ to move; only something external to both A and B could cause B to move. For Descartes, that external thing is $\mathrm{God}^{13}$. And, of course, this is generalizable to all body-body interactions. All change in body results from motion, and motion is the result of God's constantly creating matter.

The problem is clear and can be pinpointed by noting how Descartes tends to identify divine conservation and divine concurrence. In a letter to Mersenne and in his response to Hyperaspistes, 
he writes of his acceptance of divine concurrence but describes a view that can only be described as conservation ${ }^{14}$. Descartes never explains concurrence except by appealing to conservation. Divine concurrence requires that there be secondary causes with which God can concur, but in Descartes' world of extended things there is nothing that could serve as a secondary cause. All changes are due to the motion caused by God's eternal recreation, and finite objects are causally impotent.

It should be noted that Leibniz could have been influenced by this sort of argument even if Descartes is not completely responsible for it. There is no doubt that the argument, which began to gain prominence in the late 1660 's, is a characteristically Cartesian argument. Consider, for example, the early Cartesian Louis de la Forge, who made the following three claims. First, we clearly and distinctly conceive of body as purely passive and containing no active force. Second, motion is nothing more than a mode of a body and, as such, cannot pass from one body to another. Third, God conserves the world in the sense that he creates it ex nihilo at each moment. La Forge concluded that occasionalism must obtain in the context of body-body interaction: no body can move itself or another body, and, therefore, no body can cause any natural events.

When Garber calls Leibniz an occasionalist, he interprets Leibniz as accepting a Cartesian view of this sort. Thus, when Garber writes that "Leibniz held that God is the only real source of activity in the world and real cause of motion in the physical world" "I I believe he is understanding Leibniz to have held the sort of view outlined above. This view stems from the four claims in the letter to Thomasius previously discussed, and it asserts that the lack of internal dynamism in a mechanistic world without substantial forms, the fact that all change is caused by motion and the fact that God causes motion through continual recreation entails occasionalism.

But Leibniz's account of causality in the letter to Thomasius of 1669 is not occasionalistic. While he held the four 'mechanist' claims, the early Leibniz was not simply a mechanical philosopher. Rather, he was a reformer". While he accepts the "rule which is common to all these renovators of philosophy [i.e., the mechanists]" ${ }^{, 17}$, he also proclaims his determination to reconcile 
the mechanical philosophy with Aristotelianism. Thus, he writes that "the one question is whether Aristotle's abstract theories of matter, form, and change can be explained by magnitude, figure, and motion"18. For the purposes of this paper, Leibniz's attempt to bring mechanism into accordance with an Aristotelian notion of substance is particularly relevant.

Cartesianism naturally tends towards occasionalism because res extensa, of which all corporeal things are supposedly constituted, does not contain and cannot produce motion. As we have seen, Leibniz accepts an analogue of res extensa. He writes, "primary matter is mass itself, in which there is nothing but extension and antitypy or impenetrability" "19. Leibniz identifies Aristotelian primary matter and Cartesian res extensa. However, Leibniz strikingly differs with Cartesianism in that he does not believe that matter is a substance, as the following considerations show. First, Leibniz accepts the Aristotelian notion that substances are self-sufficient ${ }^{20}$. Something is self-sufficient in the Aristotelian sense only if all of its properties can be explained by its nature. Second, Leibniz accepts the mechanist claim that all corporeal properties can be explained in terms of motion, figure and magnitude. Third, motion is not a part of the nature of matter, and matter has a figure only because motion acts on $\mathrm{it}^{2 !}$. Matter is a continuous and homogenous mass", but division "comes from motion, the bounding of parts comes from division, their figures comes from this bounding, and forms from figures; therefore, forms come from motion"23. Motion produces figure by acting upon matter to divide and bound portions of it. While corporeal properties are explained by magnitude, figure and motion, figure and motion are not included in and cannot be produced from the nature of matter alone. Consequently, matter alone cannot explain a corporeal thing's properties. By itself, matter is incapable of having any properties but extension and antitypy. Leibniz believes that matter is not causally self-sufficient, for which reason he denies that it is a substance.

Because of the insubstantiality of matter, Leibniz draws a very non-Cartesian distinction between matter and body ${ }^{24}$. He writes,

we can assume nothing in bodies which does not follow from the definition of extension and 
antitypy. But from these concepts....Motion itself is not derived....Hence there is no motion, strictly speaking, as a real entity in bodies. I have demonstrated, instead, that whatever moves is continuously created and that bodies...are nothing at any time midway between the instants in motion... ${ }^{25}$.

This passage is unclear because Leibniz fails to distinguish between matter (prime matter) and body. Nonetheless, it is clear that a distinction is being drawn between bodies in which 'there is no motion' and 'continuously created' bodies that move and are nothing between the instants of motion. I believe the distinction is based on the following reasoning. To be a proper substance, body must account for magnitude, form and motion; it must be the product of the interaction between matter and motion. In this interaction the true Aristotelianism of Leibniz's account of substance is clear. Matter (primary matter) is nothing but a continuous, homogenous passive mass until it is acted upon by an active force (motion) that divides matter into forms and sustains their organization. Body is matter that has been organized into a form by motion. It exists only insofar as the acting of motion upon its matter is constant, for body loses its form and reverts to matter as soon as motion stops 'activating' it ${ }^{26}$. In short, body is formed matter, and form is matter in motion. As we have seen, motion is just God's creation of things in different places. In other words, it is God's constant recreation of matter in organized forms that provides the activity to the passive matter of bodies. Matter is substance only insofar as it is being conserved as a body by motion (i.e., by God's creative power). Because body consists of matter in motion and has a form, it can explain its properties. For this reason, Leibniz takes body rather than matter to be substance.

Keeping in mind Leibniz's distinction between body and matter and his Aristotelian notion of corporeal substance as matter organized by motion, it is possible to understand how Leibniz avoids occasionalism. Whereas the Cartesian corporeal world of res extensa is a morass of undifferentiated extended stuff, Leibniz's corporeal world consists of organized bodies with figures formed by God. Despite the prima facie contradiction, Leibniz believes 
that once matter is organized it can operate as a cause of motion, as he explains in the following passage:

form is indeed the cause and principle of motion, but not the primary one. No body moves unless it is moved from without....For example, assume a sphere to be on a plane. If it is once at rest, it will not move by itself in all eternity, unless an external impulsion is added, for example, another body. In that case the other body is the cause of the impressed motion....I admit therefore that form is the principle of motion within its own body, and that body is itself the principle of motion in another body. But the first principle of motion is the primary form [which, in the case of corporeal things, is God]",27.

This picture is clearly analogous to the scholastic picture in which God conserves things and endows them with substantial forms that have powers of their own. In this view, there are secondary causes to the extent that God continues to create things and endow them with dynamic causal powers. Leibniz rejects the substantial forms of the scholastics but replaces them with organized bodies that have causal powers as long as God continually maintains their organization. Rather than having dynamic substantial forms, Leibniz's bodies are active insofar as God keeps them organized. The organization of a body is its nature, which gives the body causal efficacy. In this way, Leibniz's view avoids occasionalism.

Leibniz's concept of body might seem problematic. Cartesianism tends to collapse into occasionalism because its geometric picture of the world contains nothing that could be a secondary cause. In the mechanist picture, substantial forms are replaced by motion; the mechanist explains all change in terms of motion operating on corporeal things. For Descartes, however, God seems to be the only cause of motion, as motion appears to be nothing more than God's creating things in succeeding places. If motion is supposed to replace substantial forms and is caused directly by God, then occasionalism eventually follows. By claim- 
ing that bodies are secondary causes, isn't Leibniz making an incoherent claim? If all change is caused by motion, then bodies could cause change only by causing motion. Motion is either caused solely by God's recreating things or is caused in part by finite things. If Leibniz means to make the latter claim, he would seem to be reintroducing dynamic properties to what seems to be a world stripped of all dynamism and assigning them to things (bodies) that seem unsuited to having dynamic properties. Body, despite being organized, is still nothing but matter in a particular form, and there is nothing about being formed that entails possessing dynamic properties.

However, I believe that a case can be made for the claim that in the letter to Thomasius of 1669 Leibniz offers a coherent mechanistic account that avoids occasionalism. To see this it will be helpful to juxtapose the Cartesian position with Leibniz's. For the Cartesian, all corporeal things are made solely of res extensa and have motion only because God recreates them in different places. In other words, the nature of a Cartesian body is to be extended, and such bodies have motion as a mode insofar as God causes them to move. Moreover, all body-body causality, which must be explained in terms of local motion, can only be the result of God's constant recreation of finite things. Motion, in this sense, is only the 'transportation' of a body from "the vicinity of the other bodies which are in immediate contact with it...to the vicinity of other bodies" 28 .

In the 1669 letter to Thomasius, Leibniz seems to agree that motion is nothing more than the 'transportation' of matter from one place to another through God's constant recreation of it. Likewise, Leibniz seems to agree that the nature of matter is extension (and antitypy). However, Leibniz's world includes bodies. Bodies consist of matter in motion, but they have a nature that is distinct from matter. In other words, bodies are not simply heaps of matter that are 'transported' by God. Rather, the nature of body is to be matter in motion. Whereas a 'Cartesian body' has res extensa as its nature and might be in motion, a 'Leibnizian body' has matter's being in motion as its nature. Motion is an essential part of a Leibnizian body. Consequently, a Leibnizian body has the ability to cause motion in itself and other things and, therefore, has 
causal efficacy. A Cartesian body, on the other hand, does not have causal efficacy because whatever motion it has is not part of its nature.

The Cartesian and the Leibnizian views are easily confused because Leibnizian bodies are in motion only insofar as God puts them in motion. This makes it seem as though the motion does not really belong to body at all. As we have seen, however, some scholastics believed that God had an analogous role in the context of substantial forms: they claimed that things have substantial forms to the extent that God constantly creates them with substantial forms. Such a view is compatible with the claim that finite things are secondary causes because of their dynamic substantial forms. Likewise, the claim that finite things are in motion only insofar as God puts them in motion is compatible with the claim that finite things are the source of secondary causes that are not 'supplanted or rendered otiose by God's causal activity in nature.' It is for this reason that Leibniz is not an occasionalist in the letter to Thomasius of 1669 .

\section{NOTES}

- I am grateful to Christia Mercer for her many valuable comments on an earlier version of this paper.

' D. Garber: Leibniz: Physics and Philosophy, in: N. Jolley (ed.): Cambridge Companion to Leibniz, New York 1995, p. 273.

2 Garber, pp. 272,277.

${ }^{3}$ My understanding of Leibniz's early metaphysical views has been strongly influenced by Christia Mercer's work on the subject, especially as it is presented in her forthcoming book Leibniz's Metaphysics: It's Origins and Development.

${ }^{4}$ Garber is aware that the early Leibniz accepted an Aristotelian view of substance (Garber, p.273). I believe that many of the claims made in this paper are also accepted by Garber. Consequently, it is somewhat surprising that Garber believes that Leibniz had occasionalist views in the letter to Thomasius of 1669.

5 Transl. By L. E. Loemker: Leibniz. Philosophical Papers and Letters, 2nd ed., Dordrecht 1969, p. 94. Descartes makes this sort of claim in several places. See The Philosophical Writings of Descartes, vols. 1-3 (CSMI, CSMII, CSMIII) Transl. by J. Cottingham, R. Stoothoff, 
D. Murdoch: New York 1985, CSMII, pp. 296-298, CSMI, pp. 24, 232, 247; CSMIII, p. 64.

${ }^{6}$ Loemker, p.99. Cf. CSMI, pp. 94, 285; CSMIII, pp. 208-209.

${ }^{7}$ Loemker, p. 102. Descartes defined motion as the 'transportation' of a body from "the vicinity of the other bodies which are in immediate contact with it...to the vicinity of other bodies" (CSMI, p. 233). Motion is not a real entity in body which causes motion but merely the state of a thing that is 'transported' from one locality to another.

Loemker, p. 102. Cf. CSMII, p. 33.

${ }^{9}$ Loemker, p. 102.

10 A. J. Freddoso: Medieval Aristotelianism and the Case against Secondary Causation in Nature, in: T. V. Morris (ed.): Divine and Human Action, Ithaca 1988, p. 76. This discussion of occasionalism, concurrentism and conservatism is heavily influenced by Freddoso's accounts of the three positions.

$"$ A. J. Freddoso, p. 78.

${ }^{12}$ G. Rodis-Lewis: L'Anthropologie Catesienne, Paris 1990, p. 44.

${ }^{13}$ CSMI, p. 240.

it CSMIII, p. 180 and CSMIII pp. 193-194, respectively. See J. Van Ruler: The Crisis of Causality, New York 1995, Ch.9.

${ }^{15}$ Garber, p. 277.

16 This point is convincingly made in Mercer's forthcoming book (C. Mercer: Leibniz's Metaphysics: It's Origins and Development). Garber (p. 273) is also aware that Leibniz is not a typical mechanist.

${ }^{17}$ Loemker, p. 94.

${ }^{18}$ Loemker, p. 95.

19) Loemker, p. 95.

20 Mercer and Sleigh's discussion of this point is quite convincing (C. Mercer, R. C. Sleigh: Metaphysics: The Early Period to the Discourse on Metaphysics, in: N. Jolley (ed.): Cambridge Companion to Leibniz, New York 1995, pp. 76-78.) Also see Garber, p. 273.

${ }^{21}$ Loemker, p. 96.

22 Loemker, p. 95.

${ }^{23}$ Loemker, p. 96.

${ }^{24}$ For a thorough account of this distinction, see Mercer/Sleigh, pp.

74-75.

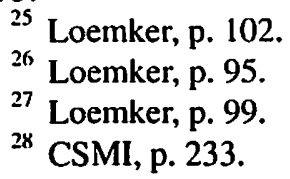

